\title{
Soja Integral Processada (Fermentada e Extrusada) e Farelo de Soja em Substituição ao Leite em Pó em Dieta de Leitões Desmamados aos 14 Dias de Idade ${ }^{1}$
}

\author{
José Luis Soares ${ }^{2}$, Juarez Lopes Donzele ${ }^{3}$, Rita Flávia Miranda de Oliveira ${ }^{3}$, Aloízio Soares \\ Ferreira $^{3}$, Célia Lúcia de Luces F. Ferreira ${ }^{4}$, Melissa Izabel Hannas ${ }^{5}$, Lourdes Romão Apolônio ${ }^{6}$
}

RESUMO - O experimento foi realizado para avaliar o efeito da utilização de soja integral fermentada (SIF), soja integral extrusada (SIE) e farelo de soja (FS), em substituição ao leite em pó (LP) da dieta, sobre desempenho e alterações morfológicas do sistema digestivo de leitões dos 14 aos 35 dias e dos 14 aos 56 dias e o seu efeito residual dos 36 aos 56 dias de idade. Foram utilizados 96 leitões machos, mestiços (Landrace x Large White), desmamados aos 14 dias de idade, em delineamento inteiramente casualizado com quatro tratamentos, quatro repetições e seis animais por unidade experimental. A fonte de proteína influenciou o desempenho dos leitões dos 14 aos 35 e dos 14 aos 56 dias de idade. Os animais que receberam dieta com LP apresentaram maior ganho de peso nas três primeiras semanas após o desmame e no período total. No entanto, no período de 36 aos 56 dias, não se observou influência dos tratamentos sobre o desempenho dos animais. Verificou-se efeito da fonte de proteína na altura de vilosidade (AV), na relação vilosidade: cripta dos leitões abatidos aos 21 dias de idade e na AV dos animais abatidos com 35 dias de idade. Os animais que receberam dieta com LP apresentaram maior AV que os dos demais tratamentos. Concluiu-se que o LP pode ser substituído pela SIE e pelo FS nas dietas de leitões desmamados aos 14 dias de idade e os altos níveis de fatores antitripsina na SIF comprometeram os resultados.

Palavras-chave: desempenho, morfologia intestinal, soja fermentada, suíno

\section{Whole Processed (Fermented and Extruded) Soybean and Soybean Meal in Replacement of Dried Milk in Diet of Piglets Weaned at 14 Days of age}

\begin{abstract}
The experiment was carried out to evaluate the effect of the use of whole fermented soybean (WFS), whole extruded soybean (WES) and soybean meal (SBM) in replacement to the dried milk (MD) of the diet on the performance, feed intake and morphological alterations on the digestive system of piglets from 14 to 35 day and from 14 to 56 days, and its residual effects from 36 to 56 days of age. Ninety-six crossbreed (Landrace x Large White) piglets weaned at 14 days of age were allotted to a completely randomized experimental design with four treatments, four replicates and six animals per experimental unit. The protein source affected the piglets performance from 14 to 35 days and from 14 to 56 days of ages. The piglets that were fed MD based diet showed better weight gain on the first three weeks after weaning and on the total period. However, from 36 to 56 days of age it was not observed the influence of the treatments on the piglets performance. It was observed effect of protein source on villus height (VH) and villus: cripta ratio of pigs slaughtered at 21 days of age, and on the VH of the piglets slaughtered at 35 days of age; pigs fed MD based diets showed higher VH than other treatments. Whole extrude soybean and SBM can replace the MD in diets of piglets weaned at 14 days of age and that the high level of anti-trypsin factors in the WFS compromised the results.
\end{abstract}

Key Words: fermented soybean, intestinal morphology, performance, swine

\section{Introdução}

A redução na idade de desmame vem sendo amplamente adotada pela indústria suinícola, objetivando melhoria no desempenho e incremento no número de partos/porca/ano realizados na granja (HOLTKAMP, 1995).

A desmama precoce requer, no entanto, que o leitão receba dieta com alta digestibilidade e valor nutritivo. Para isso, as dietas têm sido formuladas com níveis elevados de leite em pó, desnatado ou integral, como principal fonte de proteína (MASCARENHAS, 1997), o que tem elevado o custo das dietas para os animais nesta fase e, por conseguinte, o custo total da produção de suínos.

O farelo de soja, devido à sua grande disponibili-

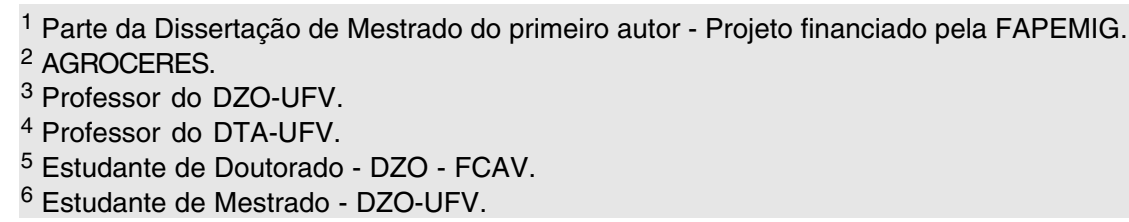


dade no mercado, pode constituir-se em opção economicamente viável para o desmame precoce, principalmente pelo seu excelente balanço de aminoácidos (THOMAZ, 1996). Entretanto, seu uso nas dietas iniciais tem sido restrito, uma vez que o farelo de soja, mesmo que processado adequadamente, possui fatores alergênicos, como as frações protéicas, glicinina e $\beta$-conglicinina, que provocam reação de hipersensibilidade no leitão, o que compromete a integridade da mucosa intestinal (GRANT, 1989) e, conseqüentemente, o desempenho dos animais. Outra opção seria a utilização de soja integral ou semi-integral processada, a qual tem inativados os fatores antinutricionais (BENATI, 1998). Esta opção ainda tem a vantagem de reduzir a adição de óleos ou gorduras nas dietas, uma vez que a soja integral tem óleo incorporado e, por conseguinte, apresenta maior valor energético que o farelo. Vários tipos de processamento da soja estão disponíveis, como a tostagem por tambor rotativo, o "jet sploder", a micronização, a extrusão, a fermentação, entre outros.

O desempenho dos leitões nas primeiras semanas após o desmame, em razão de diferentes fontes de alimentos ou diferentes níveis protéicos nas dietas experimentais, tem sido avaliado isoladamente em várias pesquisas. Os resultados do desempenho apresentado pelos leitões nesta fase têm reflexo no desempenho total do animal, sendo influenciado pelo peso e pela idade de abate.

Dessa forma, torna-se necessário avaliar os efeitos da utilização da soja integral extrusada e fermentada e do farelo de soja, em substituição ao leite em pó da dieta, sobre o desempenho dos leitões desmamados aos 14 dias de idade e o efeito residual até 56 dias de idade.

\section{Material e Métodos}

O experimento foi conduzido no Setor de Creche da Granja Santa Juliana, da empresa AGROCERES PIC, situada em Patos de Minas, MG.

Foram utilizados 96 leitões machos mestiços (Landrace $\mathrm{x}$ Large White), desmamados aos 14 dias de idade em sistema de múltiplos sítios, distribuídos em delineamento inteiramente casualizado com quatro tratamentos (diferentes fontes de proteína: leite em pó, farelo de soja, soja integral fermentada e soja integral extrusada), quatro repetições e seis animais por unidade experimental.

Os animais foram alojados em creches suspensas com laterais teladas e piso parcialmente ripado, dotadas de resistências suspensas para aquecimento dos animais, comedouros tipo cocho e bebedouros tipo chupeta. Estas creches, localizadas em prédio de alvenaria com piso de concreto, possuíam cortinas laterais para controle da ventilação.

As dietas experimentais, isolisínicas e isoenergéticas (Tabela 1), foram formuladas sob o conceito da proteína ideal (CHUNG et al., 1992), para atender ou exceder às exigências nutricionais dos animais de acordo com o NATIONAL RESEARCH COUNCIL - NRC (1998), e fornecidas à vontade aos animais dos 14 aos 35 dias de idade. Após este período, até os 56 dias todos os animais receberam uma única dieta, formulada à base de milho e farelo de soja, para atender ou exceder às recomendações do NRC (1998), para animais de 10 a $20 \mathrm{~kg}$. Os animais receberam água à vontade.

Durante os períodos experimental e pós-experimental, dos 14 aos 56 dias de idade dos leitões, as dietas, as sobras e os animais foram pesados semanalmente para determinação do ganho de peso, do consumo de ração e da conversão alimentar.

As análises bromatológicas dos ingredientes e das rações foram realizadas, de acordo com a metodologia descrita por SILVA et al. (1990), no Laboratório de Nutrição Animal do Departamento de Zootecnia da Universidade Federal de Viçosa (UFV).

A determinação de inibidores de proteases foi realizada pelo método de ERLANGER et al. (1961), utilizando-se tripsina bovina e D,L-BapNA como substrato. A mistura foi agitada e a absorvância da solução, medida a $410 \mathrm{~nm}$, durante dois minutos. As análises foram feitas em triplicatas.

A porcentagem de inibição foi calculada a partir das leituras do contraste da enzima e do teste. Os resultados foram convertidos em $\mathrm{mg}$ de tripsina pura, inibida por grama de proteína, de acordo com a seguinte fórmula:

mg de tripsina inibida/g de proteína $\frac{\mathrm{AxB}}{\mathrm{Cx} 100 \mathrm{xP}}$
em que

$\mathrm{A}(410 \mathrm{~nm})=$ absorvância do padrão - absorvância da amostra;

$\mathrm{B}=$ diluição da amostra;

$\mathrm{P}=$ concentração me $\mathrm{g} / \mathrm{mL}$ de proteína dos extratos; $\mathrm{e}$

$\mathrm{C}=$ fator de tripsina, ou seja, o produto da atuação de $1 \mathrm{~mm}$ de tripsina ativa sobre o substrato D,L-BapNA dá leitura de absorvância em $410 \mathrm{~nm}$ de 0,019 (KAKADE et al., 1974).

Para avaliação morfológica, um grupo adicional de quatro animais com peso próximo à media dos animais no início do experimento foi abatido, por dessensibilização e sangramento, aos 14 dias de idade. 
Rev. bras. zootec.

Tabela 1 - Composição centesimal das rações experimentais com leite em pó (LP), soja Integral fermentada (SIF), farelo de soja (FS) e soja integral extrusada (SIE)

Table 1 - Percentage composition of experimental diets with dried milk (DM), fermented soybean (FSB), extruded soybean (ESB) and soybean meal (SBM)

\begin{tabular}{|c|c|c|c|c|}
\hline \multirow[t]{2}{*}{$\begin{array}{l}\text { Ingrediente } \\
\text { Ingredient }\end{array}$} & \multicolumn{4}{|c|}{$\begin{array}{c}\text { Fonte de proteína } \\
\text { Protein source }\end{array}$} \\
\hline & $\mathrm{LP}(D M)$ & $\operatorname{SIF}(F S B)$ & $\mathrm{FS}(S B M)$ & $\operatorname{SIE}(E S B)$ \\
\hline Milho extrusado moído (Ground extruded corn) & 45,341 & 49,908 & 38,126 & 41,587 \\
\hline LP integral (Dried milk $)^{1}$ & 8,876 & - & - & - \\
\hline LP desnatado (Dried skin milk $)^{1}$ & 27,367 & & - & - \\
\hline $\operatorname{SIF}(\text { Fermented soybean })^{1}$ & - & 30,233 & - & - \\
\hline $\mathrm{FS}(\text { Soybean meal })^{1}$ & - & - & 30,671 & - \\
\hline SIE (Extruded soybean $)^{1}$ & - & - & - & 36,897 \\
\hline Soro de leite (Dried whey) & - & 10,000 & 10,000 & 10,000 \\
\hline Açúcar (Sugarcane) & - & 4,459 & 4,459 & 4,459 \\
\hline Fosfato bicálcico (Dicalcium phosphate) & 1,759 & 2,010 & 2,526 & 1,831 \\
\hline Calcário(Limestone) & 0,256 & 0,169 & 0,268 & 0,138 \\
\hline Óleo vegetal (Soybean oil) & 9,600 & 0,000 & 10,369 & 1,586 \\
\hline DL-Met 99 (DL-methionine 99) & 0,243 & 0,170 & 0,264 & 0,239 \\
\hline Isoleucina (Isoleucine) & 0,349 & 0,110 & 0,175 & 0,182 \\
\hline L-lisina HCL (HCLL-lysine) & 0,150 & 0,006 & 0,150 & 0,150 \\
\hline L-treonina (L-threonine) & 0,381 & 0,240 & 0,304 & 0,222 \\
\hline L-triptofano (L-triptophan) & 0,031 & 0,080 & 0,023 & 0,056 \\
\hline Ácido glutâmico (Glutamic acid) & 3,000 & - & - & - \\
\hline Valina(Valine) & 0,371 & 0,095 & 0,225 & 0,223 \\
\hline Premix mineral (Trace mineral premix $)^{2}$ & 0,100 & 0,100 & 0,100 & 0,100 \\
\hline Premix vitaminas (Trace vitamin premix) ${ }^{3}$ & 0,300 & 0,300 & 0,300 & 0,300 \\
\hline Ácido orgânico (Organic acid) & 0,600 & 0,600 & 0,600 & 0,600 \\
\hline $\operatorname{Sal}($ Salt $)$ & 0,264 & 0,420 & 0,428 & 0,418 \\
\hline BHT & 0,012 & 0,012 & 0,012 & 0,012 \\
\hline \multicolumn{5}{|l|}{$\begin{array}{l}\text { Composição calculada } \\
\text { Calculated composition }\end{array}$} \\
\hline $\mathrm{PB}(C P), \%$ & 18,104 & 19,404 & 19,274 & 19,066 \\
\hline $\operatorname{EM}(M E), \mathrm{kcal} / \mathrm{kg}$ & 3646 & 3659 & 3700 & 3700 \\
\hline Lisina (Lysine), $\%$ & 1,59 & 1,55 & 1,55 & 1,55 \\
\hline Cálcio (Calcium), \% & 0,911 & 0,910 & 0,910 & 0,910 \\
\hline Fósforo total (Total phosphorus), \% & 0,660 & 0,660 & 0,660 & 0,660 \\
\hline
\end{tabular}

Durante o período experimental, um animal de cada repetição também foi abatido por desensibilização e sangramento, aos 21,28 e 35 de idade.

Após o abate, o intestino delgado foi retirado e dois cortes foram feitos, com aproximadamente $1 \mathrm{~cm}$ de comprimento, um longitudinal e outro transversal, de três porções do intestino, correspondendo aos 25 , 50 e $75 \%$ do seu comprimento total.

Os fragmentos foram lavados em solução fisiológica para mamíferos e mantidos em solução fixadora de Bouin por 24 horas. Após este período, as amostras foram armazenadas em álcool $70 \%$, para posterior processamento no Laboratório de Morfofisiologia
Animal do Departamento de Biologia Animal da UFV.

As amostras foram desidratadas em álcool etílico, clarificadas com xilol e incluídas em parafina $\left(56-58^{\circ} \mathrm{C}\right)$, segundo as técnicas de rotina (HUMASON, 1972).

Após a inclusão, o material foi seccionado em OLYMPUS CUT 4055, obtendo-se secções de $5 \mu \mathrm{m}$ de espessura, para a montagem das lâminas. As secções foram submetidas às técnicas de desparafinização e hidratação (HUMASON, 1972) e coradas pelo método da hematoxilina:eosina.

As análises morfométricas dos cortes foram realizadas em microscópio OLYMPUS BX50, com aumento de quatro vezes, e analisador de imagem 
"IMAGE - PRO PLUS 1.3.2" (1994), no Laboratório de Histologia do Departamento de Zootecnia da UFV. Foram selecionadas e medidas 30 vilosidades e 30 criptas, bem orientadas, por lâmina.

As análises estatísticas das variáveis de desempenho (ganho de peso, consumo de ração e conversão alimentar), altura de vilosiades, profundidade de cripta e relação vilo:cripta foram realizadas, utilizando-se o programa computacional SAEG (Sistema de Análises Estatísticas e Genéticas), desenvolvido pela UNIVERSIDADE FEDERAL DE VIÇOSA - UFV (1997). As médias dos tratamentos foram comparadas pelo teste Newman-Keuls a 5\% de probabilidade.

\section{Resultados e Discussão}

Os resultados do desempenho dos leitões desmamados aos 14 dias de idade, consumindo dietas com leite em pó (LP), soja integral fermentada (SIF), farelo de soja (FS) ou soja integral extrusada (SIE), no período de 14 a 35 dias, e dieta única dos 36 aos 56 dias de idade, são apresentados na Tabela 2.

Foi observado efeito $(\mathrm{P}<0,05)$ da fonte de proteína sobre o ganho de peso diário (GPD) dos leitões, no período de 14 a 35 dias, sendo que aqueles que consumiram a dieta com LP apresentaram maior $(\mathrm{P}<0,05)$ GPD em relação aos que receberam as dietas com as outras fontes de proteína. No entanto, os animais submetidos às dietas com SIF e FS apresentaram valores de GPD iguais $(\mathrm{P}>0,05)$ entre si e maiores que aqueles que consumiram o tratamento com SIE. Tais resultados estão em acordo com os obtidos por LI et al. (1991b), RIOPÉREZ et al. (1993) e FRIESEN et al. (1993), que também observaram melhores resultados de GPD de leitões alimentados com dieta com proteína à base de leite em pó.

Os melhores resultados de GPD, obtidos com a dieta contendo LP como fonte de proteína, podem estar relacionados à maior digestibilidade da proteína do LP. De acordo com MAKKINK et al. (1994), leitões desmamados precocemente apresentam redução no consumo e desempenho, quando alimentados com proteínas vegetais, em comparação com proteínas de origem animal, sendo o leite em pó alimento altamente digestível após a desmama.

Não se constatou efeito $(P>0,05)$ dos tratamentos sobre o consumo de ração diário (CRD) dos animais. No entanto, os leitões que receberam a dieta com LP consumiram 19,9 e 44,1\% mais ração que os dos demais tratamentos.

O maior valor absoluto de consumo, verificado no tratamento em que se utilizou o LP, pode ser explicado pela possível maior digestibilidade e palatabilidade da dieta com LP. Em conformidade com este relato, TEODORO et al. (1998) constataram que dietas contendo leite em pó são mais digestíveis e palatáveis que dietas formuladas com carboidratos e proteínas de origem vegetal, nas primeiras semanas após o desmame. Por outro lado, TOPLIS e TIBBLE (1995) afirmaram haver relação inversa entre o coeficiente de digestibilidade da dieta e o consumo diário, e constataram redução de 40,23\% no consumo dos leitões, em razão da diminuição na digestibilidade da dieta de 85 para $75 \%$.

Os tratamentos influenciaram a conversão alimentar (CA) com os leitões alimentados com dieta contendo SIE apresentando pior resultado $(\mathrm{P}<0,05)$ em relação àqueles dos demais tratamentos, que, por sua vez, exibiram CA semelhantes $(\mathrm{P}>0,05)$ entre si. Apesar de a variação da CA não ter sido significativa entre os tratamentos que utilizaram LP, SIF ou FS como fonte de proteína, constatou-se melhoria de 12,9 e $15,4 \%$ na CA dos leitões que receberam dieta com LP em relação aos que receberam as dietas com FS e SIF, respectivamente. Estes resultados corroboram o relato anterior de que o melhor resultado do GPD dos animais alimentados com a dieta com LP estaria relacionado à maior digestibilidade desta dieta.

Os resultados de concentração de inibidor de tripsina (AIT) no FS, SIF e SIE encontram-se na Tabela 3. Entre as fontes de proteína de soja, somente o FS apresentou AIT abaixo do nível-limite de $20 \%$ (MONTEIRO, 1996). Com base nestes resultados, pode-se deduzir que os piores resultados de GPD e CA dos leitões que receberam a dieta com SIE podem ser explicados pelo seu alto conteúdo de AIT. Mesmo em relação à SIF, o fato desta possuir concentração de AIT 30\% maior que a do FS estaria indicando que os resultados de desempenho obtidos com esta fonte de proteína podem ter sido influenciados negativamente, quando comparados com os obtidos com o FS.

Segundo com GRANT (1989), leitões jovens têm seu desempenho comprometido quando consomem soja com altos níveis de fatores antinutricionais. A presença destes fatores ativos na dieta resulta em redução no consumo de ração e comprometimento da digestão e absorção de $\mathrm{N}$ e da utilização dos nutrientes da dieta.

Não se observou variação significativa $(\mathrm{P}>0,05)$ no desempenho dos leitões, no período de 36 a 56 dias, em razão das diferentes fontes de proteína nas dietas fornecidas no período de 0 a 21 dias após a desmama. 
Rev. bras. zootec.

Tabela 2 - Desempenho dos leitões dos 14 aos 56 dias de idade nos tratamentos com leite em pó (LP), soja integral fermentada (SIF), soja integral extrusada (SIE) e farelo de soja (FS)

Table 2 - Performance of pigs from 14 to 56 days of age on the treatments with dried milk (DM), fermented soybean (FS), extruded soybean (ES) and soybean meal (SBM)

\begin{tabular}{|c|c|c|c|c|c|}
\hline \multirow[t]{2}{*}{$\begin{array}{l}\text { Idade/Parâmetros } \\
\text { Age/Parameters }\end{array}$} & \multicolumn{4}{|c|}{$\begin{array}{l}\text { Fonte de proteína } \\
\text { Protein source }\end{array}$} & \multirow[b]{2}{*}{$\mathrm{CV}(\%)$} \\
\hline & $\begin{array}{l}\mathrm{LP} \\
D M\end{array}$ & $\begin{array}{l}\text { SI } \\
F S\end{array}$ & $\begin{array}{l}\text { FFS } \\
S B M\end{array}$ & $\begin{array}{c}\text { SIE } \\
E S\end{array}$ & \\
\hline $\begin{array}{l}\text { Peso inicial } \\
\text { Initial weight }\end{array}$ & 4,79 & 4,89 & 4,85 & 4,83 & \\
\hline 14-35 dias (days) & & $\begin{array}{l}\text { Dieta } \\
\text { Expe }\end{array}$ & $\begin{array}{l}\text { erimenta } \\
\text { ental diet }\end{array}$ & & \\
\hline $\begin{array}{l}\text { Ganho de peso diário (g/dia) } \\
\text { Average daily gain (g/day) }\end{array}$ & $267^{\mathrm{a}}$ & $189^{\mathrm{b}}$ & $209^{b}$ & $110^{\mathrm{c}}$ & 14,89 \\
\hline $\begin{array}{l}\text { Consumo de ração diário (g/dia) } \\
\text { Daily feed intake (g/day) }\end{array}$ & 307 & 256 & 277 & 213 & 19,75 \\
\hline $\begin{array}{l}\text { Conversão alimentar } \\
\text { Feed:gain ratio }\end{array}$ & $1,15^{\mathrm{b}}$ & $1,36^{\mathrm{b}}$ & $1,32^{\mathrm{b}}$ & $1,86^{\mathrm{a}}$ & 13,96 \\
\hline 36-56 dias (days) & & & $\begin{array}{l}\text { única } \\
\text { diet }\end{array}$ & & \\
\hline $\begin{array}{l}\text { Ganho de peso diário (g/dia) } \\
\text { Daily weight gain (g/day) }\end{array}$ & 635 & 621 & 649 & 616 & 6,50 \\
\hline $\begin{array}{l}\text { Consumo de ração diário }(\mathrm{g} / \mathrm{d}) \\
\text { Daily feed intake }(\mathrm{g} / \text { day })\end{array}$ & 940 & 898 & 922 & 843 & 10,38 \\
\hline $\begin{array}{l}\text { Conversão alimentar } \\
\text { Feed:gain ratio }\end{array}$ & 1,48 & 1,45 & 1,42 & 1,37 & 9,22 \\
\hline 14-56 dias (days) & & & $\begin{array}{l}\text { do total } \\
\text { period }\end{array}$ & & \\
\hline $\begin{array}{l}\text { Ganho de peso diário (g/dia) } \\
\text { Daily weight gain (g/day) }\end{array}$ & $449^{\mathrm{a}}$ & $398^{a b}$ & $424^{\mathrm{ab}}$ & $361^{b}$ & 9,16 \\
\hline $\begin{array}{l}\text { Consumo de ração diário }(\mathrm{g} / \mathrm{d}) \\
\text { Daily feed intake (g/day) }\end{array}$ & 624 & 578 & 598 & 528 & 10,93 \\
\hline $\begin{array}{l}\text { Conversão alimentar } \\
\text { Feed:gain ratio }\end{array}$ & 1,39 & 1,46 & 1,41 & 1,47 & 8,32 \\
\hline $\begin{array}{l}\text { Peso final ( } 56 \text { dias })(\mathrm{kg}) \\
\text { Final weight ( } 56 \text { days })\end{array}$ & $23,57^{\mathrm{a}}$ & $21,62^{\mathrm{ab}}$ & $22,78^{\mathrm{ab}}$ & $19,72^{\mathrm{b}}$ & \\
\hline
\end{tabular}

Médias, na linha, seguidas por letras diferentes são diferentes $(\mathrm{P}<0,05)$ pelo teste SNK.

Means, within a row, followed by different letters are different $(P<.05)$ by SNK test.

Tabela 3 - Atividade dos inibidores de tripsina no farelo de soja, na soja integral fermentada e na soja integral extrusada ${ }^{1}$

Table 3 - Activity of inhibitors of proteases on soybean meal, fermented soybean and extruded soybean ${ }^{1}$

Fontes protéicas mg de tripsina inibida/ \% de inibição Proteinsource grama de proteína \% of inhibition mg of inhibited trypsin/ gram of protein

\begin{tabular}{|c|c|c|}
\hline Farelo de soja & 19,63 & 15,76 \\
\hline Soybean meal & & \\
\hline $\begin{array}{l}\text { Soja integral fermentada } \\
\text { Fermented soybean }\end{array}$ & 37,51 & 20,59 \\
\hline $\begin{array}{l}\text { Soja integral extrusada } \\
\text { Extruded soybean }\end{array}$ & 60,52 & 96,61 \\
\hline
\end{tabular}

As vantagens de maior crescimento e maior eficiência de utilização do alimento, proporcionadas pela dieta com LP no período inicial, não persistiram no período subseqüente (36 a 56 dias), quando os leitões passaram a receber dieta comum, à base de milho e farelo de soja. Já os leitões que haviam recebido o tratamento com SIE apresentaram recuperação de sua capacidade de crescimento, apesar de terem exibido os menores resultados de desempenho nas três primeiras semanas de pós-desmama.

As perdas da vantagem comparativa de dietas com LP fornecidas nas primeiras semanas de pós-desmame também foram observadas por LI et al. (1991b) e FRIESEN et al. (1993). 
SOARES et al.

Com base nestes resultados, deduziu-se que a redução comparativa do ritmo de crescimento, no período de 36 a 56 dias, dos leitões que receberam o tratamento com LP pode, em parte, ser explicada pela possível reação de hipersensibilidade transitória às proteínas alergênicas da soja no início daquele período, já que os referidos animais não tinham tido contato com tais proteínas. Segundo SHURSON et al. (1998), a reação de hipersensibilidade às proteínas alergênicas ocorre no primeiro contato do animal com estas proteínas, independentemente da idade do suíno.

Considerando o período total, 14 a 56 dias, constatou-se efeito $(\mathrm{P}<0,05)$ dos tratamentos sobre o GPD dos animais em relação àqueles que receberam dieta com LP, apresentando maior GPD em relação aos submetidos aos tratamentos com SIE. Os leitões que receberam FS e SIF exibiram GPDs intermediários, que não deferiram dos demais tratamentos. Estes resultados estão em acordo com os de HOWIE et al. (1997), os quais relataram que o fornecimento de dieta complexa contendo proteína de plasma "spray-dried", para leitões desmamados entre 11 e 14 dias de idade, proporcionou maiores resultados de GPD e CA nas duas primeiras semanas de pós-desmama, mas não diferiu da dieta simples, à base de milho e soja, quando se considerou o período total de 0 a 49 dias após a desmama.

Os resultados de GPD médio verificados no período de 14 a 56 dias de idade, com os tratamentos LP e FS (449 e $424 \mathrm{~g} /$ dia, respectivamente), foram maiores que os observados por LI et al. (1991b) e FRIESEN et al. (1993) e semelhantes aos obtidos por O'QUINN et al. (1997), que compararam o uso de dietas à base de LP e soja. As variações de resultados verificadas em diversos trabalhos podem estar relacionadas, entre outros fatores, ao status sanitário dos animais.

No presente trabalho, considerando a média de peso dos leitões aos $14(4,84 \mathrm{~kg})$ e aos 56 dias de idade $(21,92 \mathrm{~kg})$ e o fato de terem sido os animais provenientes de granja que adotava o sistema de múltiplos sítios para controle de transmissão de doenças, podese inferir que os animais tinham bom status sanitário, o que pode ter contribuído para o seu bom desempenho, mesmo com dietas contendo alta porcentagem de produtos de soja naquele período. Segundo O'QUINN et al. (1997), leitões desmamados precocemente, com alto status sanitário, têm capacidade imunológica para suportar a adição de até $40 \%$ de farelo de soja nas dietas de pós-desmama, sem comprometer sua taxa de

crescimento e seu consumo de dieta.

De acordo com relato feito por SHURSON et al. (1998), é importante proporcionar o contato do leitão com as proteínas antigênicas da soja desde a desmama, promovendo-se a adaptação do animal a estes produtos. Ainda segundo estes autores, a inclusão de 20 a $40 \%$ de farelo de soja em dietas complexas para leitões desmamados aos 12 dias de idade não influencia negativamente o desempenho do animal.

Apesar do bom desempenho dos animais submetidos ao tratamento com SIE, no período de 36 a 56 dias de idade, o peso aos 56 dias diferiu $(\mathrm{P}<0,05)$ daqueles obtidos pelo tratamento com LP, evidenciando que altos níveis de fator inibidor da tripsina comprometeram o desempenho destes animais no período total.

Os resultados da altura de vilosidades (AV), da profundidade de criptas (PC) e da relação vilosidade: cripta (RVC) dos leitões abatidos aos 14, 21, 28 e 35 dias de idade, em razão dos tratamentos avaliados, são apresentados na Tabela 4.

Considerando que dentro de cada tratamento e idade os resultados de AV, PC e RVC não variaram significativamente entre as diferentes regiões do intestino delgado amostrados, os dados apresentados na Tabela 4 representam a média dos valores obtidos das três porções analisadas de cada animal.

Em conformidade com este trabalho, diferentes autores (TEIXEIRA, 1999; ABREU, 1994) também não observaram variação significativa na altura das vilosidades, na profundidade das criptas e na relação vilosidade: cripta entre as três diferentes regiões do intestino delgado de leitões, dentro de um mesmo tratamento e idade (14, 21, 28 e 35 dias).

Comparando os valores médios obtidos de AV e PC dos leitões abatidos aos 14 dias (desmama) com aqueles dos animais submetidos aos diferentes tratamentos e abatidos aos 21,28 e 35 dias de idade, constatou-se que a AV reduziu, em média, $47,3 \%$ na primeira semana de pós-desmama (21 dias) e, posteriormente, iniciou recuperação gradual, de forma que, aos 35 dias de idade, a redução da AV em relação aos 14 dias correspondeu a $29,1 \%$. A PC aumentou gradualmente de 36,5 a $92,2 \%$, aos 21 e 35 dias, respectivamente, em relação aos 14 dias. Tais resultados corroboram o relato de LE DIVIDICH et al. (1998), CERA et al. (1988) e THOMAZ (1996) de que alterações na morfologia intestinal de pós-desmama são transitórias e caracterizadas por redução da AV entre 27 e $59 \%$ e aumento na PC entre 10 e $114 \%$, na primeira semana após a desmama. A partir da primeira semana após a desmama, a AV volta a aumentar e se estabiliza. 
Rev. bras. zootec.

Tabela 4 - Altura de vilosidade, profundidade de cripta e relação vilosidade/cripta do intestino delgado aos 14, 21, 28 e 35 dias de idade, nos tratamentos com leite em pó (LP), soja integral fermentada (SIF), soja integral extrusada (SIE) e farelo de soja (FS)

Table 4 - Villus height, crypt depth and villus:crypt ratio of the small intestine at 14, 21, 28 and 35 days of age on the treatments with dried milk (DM), fermented soybean (FS), extruded soybean (ES) and soybean mea (SBM)

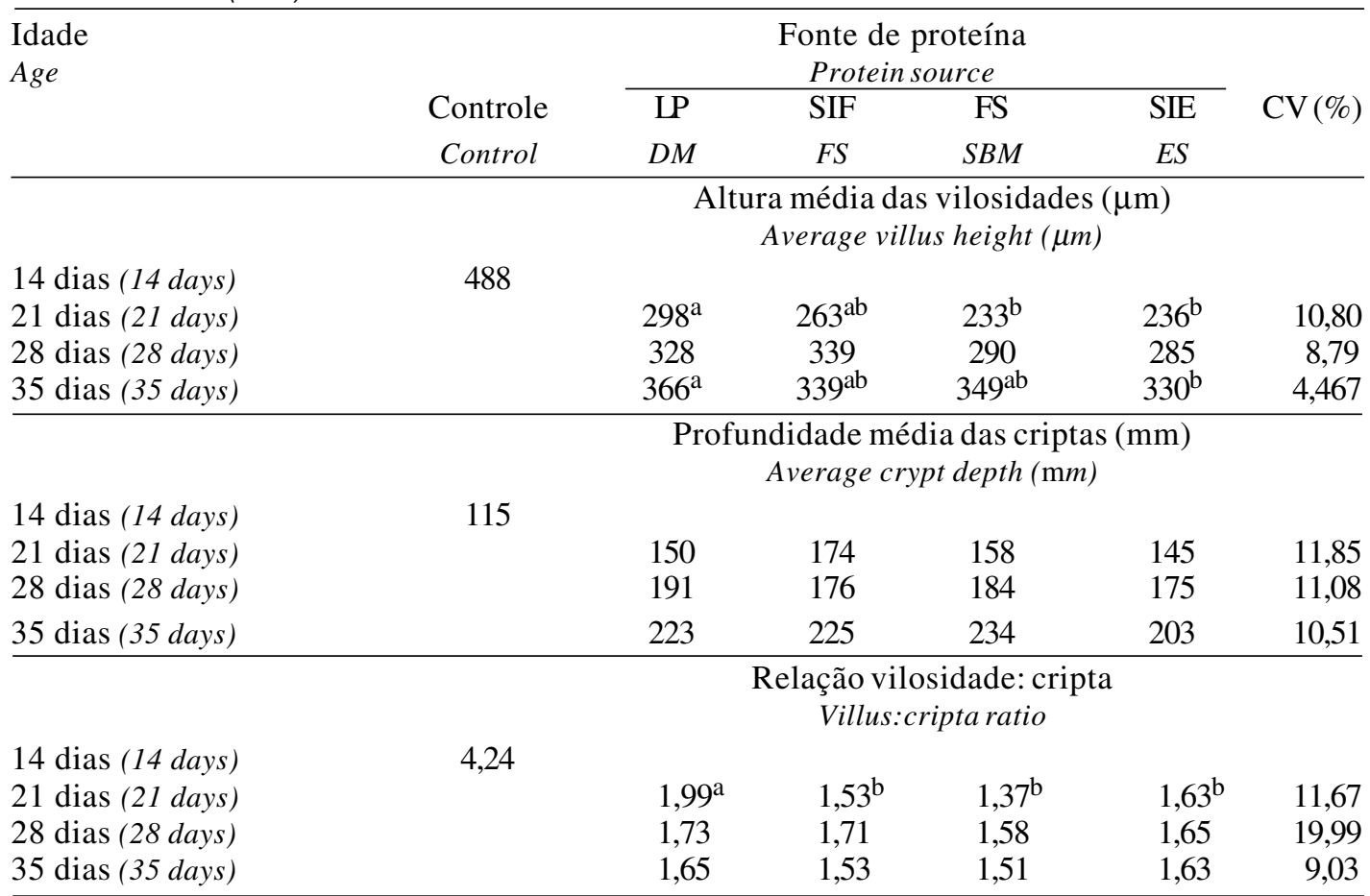

Médias, na linha, seguidas por letras diferentes são diferentes $(\mathrm{P}<0,05)$, pelo teste SNK.

Means, within a row, followed by different letters are different $(P<.05)$ by SNK test.

Constatou-se efeito $(\mathrm{P}<0,05)$ da fonte de proteína na AV dos leitões aos 21 dias de idade, sendo que os animais que consumiram dieta com LP apresentaram maior $(\mathrm{P}<0,05) \mathrm{AV}$ que os leitões que consumiram dieta com SIE e FS. Os leitões que receberam dieta com SIF exibiram AV intermediária, que não diferiu $(\mathrm{P}<0,05)$ das AV dos demais tratamentos.

Resultados semelhantes foram observados por LI et al. (1990, 1991a), que também verificaram melhor integridade de mucosa nos leitões alimentados com dieta à base de LP, em comparação com dietas com produtos de soja.

A maior AV que, provavelmente, resultou em maiores áreas absortiva e digestiva no intestino delgado, observadas nos leitões que consumiram dieta com LP, pode ser explicada pelo fato de o LP não possuir proteínas alergênicas e por conter diferentes fatores de crescimento na sua composição, os quais promovem recuperação mais rápida da mucosa intestinal dos leitões após a desmama.

De acordo PLUSKE et al. (1995) e ODLE et al. (1996), o leite contém na sua composição fatores de crescimento, como EGF, IGF-I, IGF-II, insulina, que atuam estimulando a divisão e a diferenciação celular no intestino delgado e promovendo a regeneração mais eficiente da mucosa intestinal.

As menores AV observadas nos leitões aos 21 dias de idade, que receberam dietas com FS e SIE, podem estar relacionadas aos fatores antigênicos, como glicinina e $\beta$-conglicinina presentes na soja, e ao baixo CRD dos animais.

De acordo com LI et al. (1990, 1991a) e THOMAZ (1996), os fatores antigênicos da soja provocam reação de hipersensibilidade transitória em leitões, que se caracteriza por atrofia das vilosidades e aumento da profundidade das criptas. Posteriormente, McCRACKEN et al. (1995) e PLUSKE et al. (1996) relataram haver relação linear entre o consumo de matéria seca e a altura média das vilosidades do intestino delgado, nas primeiras semana após a desmama, com o consumo de alimento explicando $68 \%$ da variação observada na altura das vilosidades.

Não se observou efeito dos tratamentos sobre a AV dos animais aos 28 dias de idade. No entanto, verificou-se que os animais que receberam dieta com SIF apresentaram AV 18,9 e 16,9\% 
maior do que aquelas dos animais que receberam dieta com SIE e FS, respectivamente. Estes resultados indicam que, duas semanas após a desmama, a SIF proporcionou melhor recuperação da mucosa intestinal, em relação aos tratamentos com SIE e FS.

Nos animais 35 dias de idade, ocorreu efeito dos tratamentos sobre AV para aqueles que consumiram dieta com LP, os quais apresentaram maior AV $(\mathrm{P}<0,05)$ em relação aos que consumiram dieta com SIE. Os tratamentos em que se utilizaram SIF e FS como principal fonte de proteína apresentaram AV similares entre si $(\mathrm{P}>0,05)$ e não diferiram das $\mathrm{AVs}$ dos demais tratamentos.

Com relação à profundidade média das criptas, não se observou variação significativa $(\mathrm{P}>0,05)$ entre os diferentes tratamentos, em nenhuma das idades avaliadas. $\mathrm{O}$ aumento na $\mathrm{PC}$ da mucosa intestinal de leitões, nas primeiras semanas de pós-desmama, tem sido observado por diferentes autores (CERA et al., 1988; PLUSKE et al., 1996; e LE DIVIDICH et al., 1998).

A relação vilosidade: cripta média (RVC), determinada nos animais aos 14 dias de idade (desmama), diminuiu de 4,24 para 1,63 e 1,58 nos animais de $21 \mathrm{e}$ 35 dias de idade, respectivamente.

Foi observado efeito $(\mathrm{P}<0,05)$ dos tratamentos na RVC aos 21 dias de idade. Os leitões que receberam dieta com LP apresentaram maior $(\mathrm{P}<0,05) \mathrm{RVC}$ que os demais tratamentos, que não diferiram $(P>0,05)$ entre si. Não foi verificado efeito $(\mathrm{P}>0,05)$ das fontes de proteína sobre a RVC nas demais idades avaliadas.

Apesar de não terem sido verificadas diferenças significativas aos 21 dias de idade, entre os resultados de RVC obtidos nos tratamentos que continham SFI, FS e SEI, os leitões que receberam dieta com FS apresentaram RVC 10,4 e 15,9\% menor que os dos tratamentos com SFI e SEI, respectivamente. Estes resultados confirmaram a hipótese de que o FS continha maior nível de proteínas alergências que SFI e SEI.

\section{Conclusões}

O farelo de soja e a soja integral fermentada substituem o leite em pó em rações contendo soro de leite, para leitões desmamados aos 14 dias de idade. Os altos níveis de fatores inibidores da tripsina presentes na soja integral extrusada comprometeram a sua utilização nas dietas dos leitões desmamados aos 14 dias de idade.

\section{Referências Bibliográficas}

ABREU, M.L.T. Efeito da proteína do farelo de soja sobre o desempenho e ocorrência de alterações digestivas em leitões desmamados aos 21 dias de idade. Viçosa: UFV, 1994. 79p. Dissertação (Mestrado em Zootecnia) - Universidade Federal de Viçosa, 1994.

BENATI, M. Processamento de soja e suas implicações na alimentação de leitões. In: SIMPÓSIO SOBRE NUTRIÇÃO E MANEJO DE LEITÕES 1998, Campinas. Anais... Campinas: 1998. p.41-59.

CERA, K.R., MAHAN, D.C., CROOS, R.F. 1988. Effect of age, weaning and postweaning diet on small intestinal growth and jejunal morphology in young swine, J. Anim. Sci., 66:74-84.

CHUNG, T.K., BAKER, D.H. 1992. Ideal amino acid pattern for 10-kilogram pigs. J. Anim. Sci., 70:3102-3111.

ERLANGER, B.F., KOKOWSKY, N., COHEN, W. 1961.The preparation and properties of two new chromogenic substrates of trypsin. Arch. Biochem. Biophys., 95:271-278.

FRIESEN, K.G., GOODBAND, R.D., NELSSEN, J.L. et al. 1993. The effect of pre- and postweaning exposure to soybean meal on growth performance and on the immune response in the early-weaned pig. J. Anim. Sci., 71:2089-2098.

GRANT, G. 1989. Anti-nutritional effects of soybean: a review. Progress in Food and Nut. Sci., 13:317-348.

HOLTKAMP, D.J. Productivity gains related to segregated early weaning in pigs In: ANNUAL MEETING OF AMERICAN ASSOCIATION OF SWINE PRACTITIONERS, 26, 1995, Nebraska. Proceedings... Nebraska: AASP, 1995. p.217-223.

HOWIE, M. 1997. Animal proteins continue to evolve, spray dried plasma shows promise. Feedstuffs, 27:11-27.

HUMASON, G.L. 1972. Animal tissue techniques. 3.ed. São Francisco. 641p.

IMAGE - PRO PLUS 1.3.2. 1994. The proven solution for image analysis, Reference Guide.

KAKADE, M.L., RACKIS, J.J., MCGHEE, J.E. 1974. Determination of trypsin inhibitor activity of soy products: a collaborative analysis of an improved procedure. Cereal Chemistry, 51:376-382.

LE DIVIDICH, J., TIVEY, D., AUMAITRE, A. Gastrointestinal development and digestive capacity in young pig. In: IPVS CONGRESS, 15, 1998, Birmingham. Proceedings... Birmingham, 1998. p.299-308.

LI, D.F, NELSSEN, J.L., REDDY, P.G. et al. 1990. Transient hypersensitivity to soybean meal in the early-weaned pig. $J$. Anim. Sci., 68:1790-1799.

LI, D.F, NELSSEN, J.L., REDDY, P.G. 1991a. Measuring suitability of soy bean products for early-weaned pigs with immunological criteria J. Anim. Sci., 69:3299-3307.

LI, D.F, NELSSEN, J.L., REDDY, P.G. 1991b. Interrelationship between hypersensitivity to soybean proteins and growth performance in early-weaned pig. J. Anim. Sci., 69:4062-4069.

MAKKINK, C.A., BERNTSEN, P.J.M., OP DEN KAMP B.M.L. et al. 1994. Gastric protein breakdown and pancreatic enzyme activities in response to two different dietary protein source in newly weaned pigs. J. Anim. Sci., 72:2843-2850.

MASCARENHAS, A.G. Dietas simples com diferentes niveis protéicos e complexas fornecidas a leitões desmamados aos 21 dias de idade. Viçosa: UFV, 1997. 40p. Dissertação (Mestrado em Zootecnia) - Universidade Federal de Viçosa, 1997.

McCRACKEN, B.A., GASKINS, H.R., RUWE-KAISER, P.J. et al. 1995. Diet-dependent and diet-independent metabolic responses underlie growth stasis of pigs at weaning. Am. Inst. 
Rev. bras. zootec.

Nut., 2838-2845.

MONTEIRO, M.R.P. Avaliação bioquímica e nutricional do extrato hidrossolúvel obtido de farinha de soja desengordurada e emulsificada. Viçosa: UFV, 1996. Dissertação (Mestrado em Agroquímica) - Universidade Federal de Viçosa, 1996.

NATIONAL RESEARCH COUNCIL - NRC. 1998. Nutrient requirement of swine. 10.ed. Washington, D.C. 189p.

O'QUINN, P.R., NELSSEN, J.L., TOKACH, M.D. 1997. Effect of time of introduction and level of soybean meal on performance of segregated early-weaned pigs. Swine Day 1997. p.57-61 (http://www.oznet.ksu.edu/library/lvstk2/ welcome. htm\#Swine)

ODLE, J., ZIJLSTRA, R.T., DONOVAN, S.M. 1996. Intestinal effects of milkborne growth factors in neonates of agricultural importance, J. Anim. Sci., 74:2509-2522.

PLUSKE, J.R., WILLIAMS, I.H., AHERNE, F.X. 1995. Nutrition of neonatal pig: development and surviral. London: $\mathrm{CAB}$ International. p.187-235.

PLUSKE, J.R., WILliAMS, I.H., AHERNE, F.X. 1996. Maintenence of villous height and crypt depth by providing continuous nutrition after weaning. Anim. Sci., 62:131-144.

RIOPÉREZ, J., TORTUERO, F., RODRÍGEZ. A. et al. 1993. Efecto de la alimentacion com harina de soja sometida a distintos tratamientos sobre el crescimiento y morfologia intestinal del lechon. Archivos de Zootecnia, 42:125-135.

SILVA, D.J. 1990. Análise de alimentos (métodos químicos e biológicos). Viçosa: UFV. 165p.

SHURSON, J., JOHNSTON, L. 1998. Swine nutrition and health connections examined. Feedstuffs, 23:11-18.
1161

TEIXEIRA, A.O. Efeito de dietas simples e complexas sobre morfologia intestinal de leitões até 35 dias de idade. Viçosa: UFV, 1999. 79p. Dissertação (Mestrado em Zootecnia) Universidade Federal de Viçosa, 1999.

TEODORO, M.T., BERTO, D.A., PAI, V.D., PADOVANI, C.R. Desempenho de leitões lactentes e desmamados precocemente, alimentados com dietas farelada ou extrusada seca e úmida. In: REUNIÃO ANUAL DA SOCIEDADE BRASILEIRA DEZOOTECNIA, 35, 1998, Botucatu. Anais... Botucatu: SBZ, 1998. p.91-100.

THOMAZ, M.C. Digestibilidade da soja semi-integral extrusada e seus efeitos sobre o desempenho e morfologia intestinal de leitões na fase inicial. Botucatu: UNESP, 1996. 66p. Tese (Doutorado em Nutrição e Produção Animal) Universidade Estadual Paulista, 1996.

TOPLIS, P., TIBBLE, S. 1995. Piglet nutrition - theory into practice. International Pig Topics. p.11-15.

UNIVERSIDADE FEDERAL DE VIÇOSA - UFV. Sistema de análise estatísticas e genéticas - SAEG. Viçosa: 1997. (Versão 7.1).

Recebido em: 14/08/1999

Aceito em: 27/12/1999 